\title{
Manipulation of landing behaviour of two whitefly species by reflective foils
}

\author{
Jan-Uwe Niemann ${ }^{1}$ D $\cdot$ Max Menssen ${ }^{2} \cdot$ Hans-Michael Poehling ${ }^{1}$
}

Received: 24 January 2020 / Accepted: 8 October 2020 / Published online: 19 October 2020

(c) The Author(s) 2020

\begin{abstract}
Whiteflies are major pests on several vegetable and ornamental crops. Landing behaviour is strongly influenced by wavelength $(\mathrm{nm})$ of reflected light from ground and surrounding vegetation. This paper deals with manipulation of whitefly landing behaviour in semi-field greenhouse experiments using background foils, either white foils with high reflection of short wavelength radiation or green foils reducing contrast between target plants and background (soil). The reactions of two different whitefly species were compared to detect possible differences between specialist (Aleyrodes proletella) and generalist (Trialeurodes vaporariorum) species. Dual-choice experiments were performed in a greenhouse using ice-lettuce, Lactuca sativa var. capitata (T. vaporariorum) and broccoli, brassica oleracera var. Italica P (A. proletella) as model plants. The results show strong impact of the white reflective foil in controlling landing behaviour of both species, whereas the effect of the contrast-minimising foil was much lower. Light influence was stronger on generalist than on specialist species. Mechanisms behind these effects and opportunities for inclusion in an integrated pest management strategy are discussed.
\end{abstract}

Keywords Contrast minimising $\cdot$ Manipulating insect behaviour $\cdot$ Integrated pest management $\cdot$ Wavelength specific behaviour $\cdot$ Colour opponent mechanism $\cdot$ Plant protection

\section{Introduction}

Whiteflies are important pests in vegetables and ornamental plants (Byrne et al. 1990). Aleyrodes proletella L., the cabbage whitefly (Hemiptera: Aleyrodidae), represents this pest group specialised in Brassicaceae (in Europe). It is able to infest plants within 12 families (Mound and Halsey 1978), but in agriculture it is mostly found on Asteraceae and Brassicaceae (de Barro and Carver 1997; Martin 1999; Chen et al. 2007), with preference for broccoli, cauliflower and kale. Trialeurodes vaporariorum $\mathrm{W}$., the greenhouse whitefly (Hemiptera: Aleyrodidae), is very polyphagous and infests over 82 plant families including about 800 species (Mound and Halsey 1978). It is a serious pest in protected

Jan-Uwe Niemann

niemann@ipp.uni-hannover.de

1 Section Phytomedicine, Institute of Horticultural Production Systems, Leibniz-Universität Hannover, Herrenhäuser Str. 2, 30419 Hannover, Germany

2 Section Biostatistics, Institute of Cell Biology and Biophysics, Leibniz-Universität Hannover, Herrenhäuser Str. 2, 30419 Hannover, Germany cultivation systems in Europe but also in field crops in warmer climates. Whitefly infestation of open fields starts mostly at field edges (Horowitz and Ishaaya 1996; Collins 2016). Due to this hidden and protected lifestyle, chemical control is primarily effective using systemic insecticides; however, reports of insecticide resistance are numerous (Gorman et al. 2001, 2007; Luo et al. 2010; Springate and Colvin 2012). Biological control of whiteflies using natural enemies in protected cultivation systems is well established. However, under field conditions the efficacy of beneficial insects is often reduced and unreliable and the cost-benefit ratio is not reliable. Regarding the population dynamics of whiteflies, a key factor for all biological control measures is the early suppression of alighting and settlement; hence, biotechnical measures influencing host finding and settlement as discussed here could be an interesting alternative. Restrictions in plant protection law and public demands for pesticide-free products require a minimisation of the use of chemical agents. 


\section{Host plant orientation of whiteflies}

Distance orientation of whiteflies as well as descending flight and landing behaviour is well known to be mainly triggered by colours, in particular yellow, which is also the reason for whitefly trapping approaches with yellow traps (Vaishampayan et al. 1975b; Noldus and Van Lenteren, 1991; Döring and Chittka 2007; Shimoda and Honda 2013). Recently, the visual behaviour of the greenhouse whitefly was studied more in detail by Stukenberg and Poehling (2019), Stukenberg (2018), and Stukenberg et al. (2015). They showed that the preference for yellow colours is based on a colour opponent mechanism of green and blue and that target attractiveness can be much enhanced if green without inhibiting influence of blue is offered. Moreover, UV-light is relevant for whitefly orientation. Stukenberg and Poehling (2019) also confirmed Coombe (1981) who showed that $T$. vaporariorum responds differently depending on the light intensity as well as on its wavelength. Experiments about spectral sensitivity of aphids and whiteflies showed the same sensitivity peaks at $550 \mathrm{~nm}$ (Hardie 1989; Nottingham et al. 1991; Mellor et al. 1997; Döring et al. 2011). Like Legarrea et al. (2011), we assume comparable reaction in landing process in whiteflies as known for aphids, despite differences, especially in migratory and distance flight. Similarities in colour vision are evident (Prokopy and Owens 1983; Hardie 1989). The strong importance of light triggered control of host plant acceptance by whiteflies was also confirmed from virus transmission studies (Ferreres et al. 2016). Apart from light control of host plant selection, olfactory orientation is an additional key factor, which has been shown first, in particular, for the cabbage whitefly (Butler 1938; Mound 1962), possibly correlated with their host-specificity and the strong delivery of host plant-specific volatiles by Brassicaceae (Noldus and Van Lenteren 1991). For other whitefly species, the results are inconsistent, but morphological studies showed that organs for perception of olfactory stimuli are present in A. proletella and T. vaporariorum (Mellor and Anderson 1995a,b), and effects on whitefly behaviour were observed by different plant odour blends (Schlaeger et al. 2018). Furthermore, the importance of olfactory and visual cues for host plant orientation was evaluated for Bemisia tabaci. Recent studies showed additional effects of visual and olfactory cues in host plant orientation if viruses are involved (Johnston and Martini 2020). Olfactory cues will probably be used by most whitefly species for host-recognition and settlement, after landing has occurred, and similarities to aphid behaviour (Kennedy et al 1961; Prokopy and Owens 1983) are proposed by different authors (Vaishampayan et al. 1975a; Coombe 1982). Experiments to examine the olfactory stimuli on whiteflies are, however, often focused on host-recognition and host-acceptance and were not designed to evaluate descending flight and/or landing behaviour (Tsueda et al. 2014; Darshanee et al. 2017).

\section{Visual manipulation of whiteflies}

\section{Contrast}

For aphids, it is shown that the contrast between plant and soil is important for targeted landing on the host plant and that landing efficacy can be lowered if the contrast is reduced by coloured (e.g. green) backgrounds (Döring 2004, 2014; Hooks and Fereres 2006), even when the artificial background is attractive for itself (Döring and Röhrig 2016). For the whitefly species tested in this study, this is the first investigation of manipulation of landing and settling behaviour by means of artificially manipulated contrasts between plants and background. For whiteflies in general, some studies have examined barrier plants (Smith and McSorley 2000; Castle 2006) to reduce virus transmission, but colour contrast effects (Döring and Chittka 2007) have not been evaluated in detail so far.

\section{UV ratio environment}

Shifting the ratio of ambient near-UV light (UV-A) in the environment around plant stands can reduce the infestation by whiteflies. This was shown in field studies with foil tunnels which exclude the ambient UV light (Mutwiwa et al. 2005; Gulidov and Poehling 2013) and with artificially UVemitting fluorescent tube-type lamps (Mutwiwa and Tantau 2005). Experiments by Antignus et al. (2001, 2004) showed the same tendencies in laboratory and field tests with UVdeficient tunnels.

\section{Reflective foils}

Moreover, specific light reflection from the ground area around plants can strongly influence whitefly landing behaviour. In studies with reflective foils, the material and optical properties vary greatly (Greer and Dole 2003). Summers and Stapleton (2002) showed that reflective mulch films can have the same control effect on infestation levels of Bemisia argentifolii as treatments with the pesticide imidacloprid. Only one study has dealt with the reaction of whiteflies ( $B$. argentifolii) to white foil (Csizinszky et al. 1997), but reflection spectra are not given and experiments were not designed for evaluation of whitefly landing and/or settling behaviour. For aphids, the results differ greatly between studies using white foil/mulch. Some species are attracted (e.g. Aphis gossypii G.), some are repelled (e.g. Aphis spiraecola $\mathrm{P}$.) (Adlerz 1968; Antignus 2000; Greer and Dole 2003). We 
used a white foil with low UV reflectance to avoid the wellknown repellent effect known triggered by reflected UVlight $(<400 \mathrm{~nm})$. Reflection spectra for all materials were recorded to ensure comparability with other studies, which is often not possible due to a lack of (available) data, as mentioned by Döring (2014).

The aim of this study is to show basically that coloured foils reducing contrasts or foils reflecting repellent wavelengths can be an important (and cost-effective) additional physical measure for plant protection within an integrated plant management system. The results should be implemented in further developing herbivore controlling biodegradable, sprayable foil/films for use in horticultural production systems.

\section{Materials and methods}

\section{Reflection measurement}

Reflection spectra were measured with a UV/VIS/NIR spectrophotometer (Perkin-Elmer Instruments, Norwalk, USA) containing a 30-cm integrating sphere and a tungsten-halogen and deuterium lamp. Each foil sample was measured three times at different randomly selected points on the sample surface, and the mean was calculated. The reflection properties of plant leaves were measured 6 times, 3 times for the three youngest and oldest leaves, respectively. (Always upper side, central veins were excluded by positioning the sample.) Samples were measured from 300 to $700 \mathrm{~nm}$ results given in reflection percentage.

\section{Experimental plants and insects}

Lettuce plants (Lactuca sativa L. var. capitata, Rijk Zwaan, cultivar Diamantinas) were used as experimental host plant for $T$. vaporariorum. Plants were grown in 12-cm PET pots $\left(\mathrm{Teku}^{\circledR}\right)$. Growing conditions were $21^{\circ} \pm 1^{\circ} \mathrm{C}$ during the day (6 a.m. to 10 p.m.) and $17 \pm 1{ }^{\circ} \mathrm{C}$ at night time (10 p.m. to 6:00 a.m.) in a climate chamber. When lettuce plants reached the phenological BBCH (Biologische Bundesanstalt, Julius Kühn-Institut), Bundessortenamt, Chemische Industriescale) stage 16 to 18 representing seedlings with 6-8 fully developed leaves (Feller et al. 1995), they were used for the experiments.

Broccoli plants (Brassica oleracea var. italica P., Syngenta, cultivar Monrello) served as experimental host plant for the cabbage whitefly, A. proletella. Evans (2007) also reported Lactuca sp. as a potential host, however, for the lettuce cultivar used in our experiments we cannot confirm this. They were grown under the same conditions as the lettuce plants. Plants were used at phenological $\mathrm{BBCH}$ stage 15 for the experiments. BBCH stage 15 represented seedling with 5 fully developed leaves and plants had about the same leaf areas as the lettuce seedlings.

Adult whiteflies were obtained from separate rearing stocks. Aleyrodes proletella was reared on broccoli (same cultivar as in experiments), T. vaporariorum on tobacco (Nicotiana tabacum L.). Acceptance of used lettuce cultivar and reproduction by $T$. vaporariorum was confirmed before starting the main experiments. Both cultures were held at $21^{\circ} \mathrm{C}$ and $16 \mathrm{~h} \mathrm{light} \mathrm{exposure} \mathrm{(Son-t} \mathrm{Agro} 400 \mathrm{~W}$ ) in gauze-covered wooden cages with clear plastic tops (acrylic glass, $3 \mathrm{~mm}$ ). For experiments, approx. 100 whiteflies were gently removed from rearing stocks with an aspirator and transferred into a glass tube (height: $10 \mathrm{~cm}$, diameter: $2.9 \mathrm{~cm}$ ) approx. $20 \mathrm{~min}$. before the experiment started and kept in the experimental greenhouse to adapt to light conditions. Vitality was checked visually before use. During the experiments, it turned out that it was impossible to catch exactly 100 individual whiteflies for each experiment due to the high density in the insect rearing. Therefore, the numbers of whiteflies released differ slightly between the single experimental runs.

\section{Location and experimental setup}

Experiments were carried out in a greenhouse environment at $21 \pm 2{ }^{\circ} \mathrm{C}$ in the Institute of Horticultural Production Systems, Herrenhäuserstr.2, 30,419 Hannover, Germany. The size of the greenhouse cabinet was $10 \mathrm{~m} \times 10 \mathrm{~m}$. Choice experiments were performed in two flight cages (size: $1.2 \mathrm{~m} \times 6.0 \mathrm{~m} \times 2.0 \mathrm{~m}$-see Fig. 1) made of white mesh, arranged in the middle of the greenhouse, in N-S direction in a shaded greenhouse. Cages were placed in a distance of $2 \mathrm{~m}$ to each other on the long side and more than $2 \mathrm{~m}$ in each direction to the heating system. Flight cages were used to enable removing of unsettled whiteflies from the experimental arena for sequential repetitions of the experiment. Additional light (Son-t Agro $400 \mathrm{~W}$ ) was applied during experiments.

The flight cages were divided into three compartments (Fig. 1): the whiteflies release area in the middle and one settlement plot on each side of the cage. These plots $(0.8 \mathrm{~m} \times 1.2 \mathrm{~m})$ consisted of plants $(\mathrm{p})$, placed in a square ( $32 \mathrm{~cm} \times 32 \mathrm{~cm}$ planting distance) in an 8-cm high layer of planting substrate (Einheitserde P). One of the plots contained coloured test foil fixed on a wooden frame resulting in the same height $(8 \mathrm{~cm})$ as the planting substrate. Plants were placed in holes in the foil with the same planting distance. PVC foil (POLYMAR $\odot, 650 \mathrm{~g} / \mathrm{m}^{2}$, Art.nr.8210 5240) was used to create the coloured optic background. The foils were ventilated for 6 months before use to avoid interference from possible odour. 
Fig. 1 Experimental setup: Flight cage (dashed line), two plots with four plants (p) each. Background of plots (dotted or striped) is foil or soil and depends on orientation (NorthSouth or South-North) of the experiment. Starting point for the insects in the middle of the cage (with indicated whiteflies)

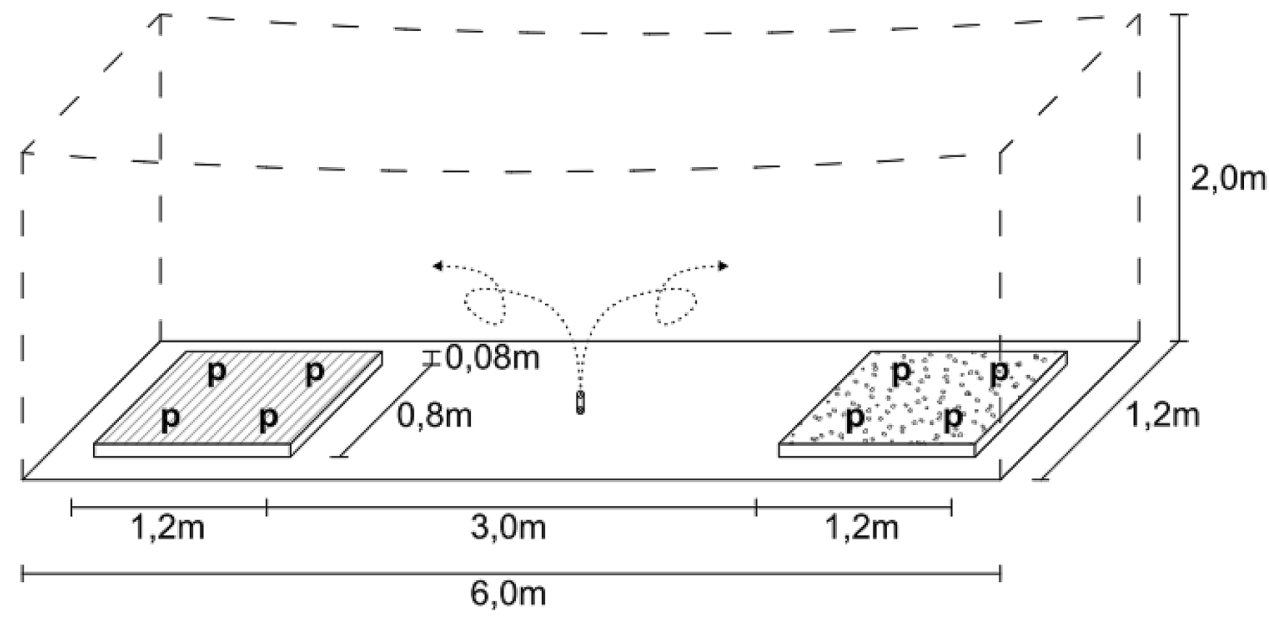

\section{Experiments}

The experiments had two different approaches:

1. Use of green foil to minimise the contrast between soil and plant. Hypothesis: Dispersing whiteflies from the central release area will be focused (landing trigger) at the edge of the foil. The start of descending flight (cf. "Beginn des Befallsflug" in Moehricke 1955), and therefore, following settling on host plants will be disturbed by minimised contrast.

We used two different foils with standardised green hues, medium-green [RAL 6001 (RAL gemeinnützige GmbH, Bonn, Germany)] and a yellow-green (RAL 6018), for the experiments to consider the different colours of the plant species. Those were chosen visually at first. Additionally, we measured the spectral reflectance (\%) of all foil and plantleaf surfaces (Fig. 2). The two different green foils showed relatively similar spectral reflectance (\%) as both plant species (see Fig. 2) and were selected for the experiments to minimise contrast between plant species and ground. The yellow-green foil visually looks more like those of the lettuce (in contrast to the medium-green foil) but differs in the spectral reflectance (\%). Due to this inconsistency, a preliminary test was done to investigate which mulch colour was more suitable to minimise contrast between lettuce plants and ground. Selection was done after preliminary tests with same conditions as described for the experiments shown here. Trialeurodes vaporariorum was tested in choice experiments to determine if soil vs. medium-green foil results in the same reduction of whiteflies on the plants as soil vs. yellow-green foil does. Since the effect of the yellow-green foil was much stronger in decreasing settlement rate of $T$. vaporariorum on lettuce than medium-green foil, we decided to use yellow-green foil for the experiments with $T$. vaporariorum, and medium-green foil for those with A. proletella, even if the statistical equivalence of the two "green" variants is affected. The selected variants for the main experiment are shown below (see also Figs. 3 and 4). The duration time for the experiments was tested in preliminary test, giving rates of recaptured whiteflies bigger than $90 \%$ after $23 \mathrm{~h}$, which also occurred in the main experiment.

2. Use of reflective white foil (RAL 9010). Hypothesis: Whiteflies will be repelled by the high reflection ( $50 \%$ up to $80 \%$ ) in the spectral range of $400-490 \mathrm{~nm}$ (see Fig. 2). This will result in induced upward flight behaviour and leaving of the target area. One white hue was used for both whitefly species and plant (lettuce and broccoli) species in the experiments.

The following four variants were selected for the main experiment:

V1 A. proletella-broccoli-medium-green foil versus soil.

V2 T. vaporariorum-lettuce-yellow-green foil versus soil.

V3 A. proletella - broccoli-white foil versus soil.

V4 T. vaporariorum - lettuce-white foil versus soil.

Experiments always started at 10 a.m. with release of approx. 100 whiteflies in the centre of the flight cages. Whiteflies settled on plants were counted the next day at 9:45 a.m. Plants and whiteflies were removed. Afterwards, the cage was cleaned with a vacuum cleaner such that the next repetition could be started with new plants and insects at 10:00 a.m.

Every experiment was repeated 10-12 times consecutively with the foil plot directed towards the south and 10-12 times with the foil plot directed towards the north. The allocation of the whitefly species to the cages (east and west) was randomised to avoid possible effects of the ambient light entering the experimental compartment. On every experimental day, there was one trial with greenhouse whitefly and one with cabbage whitefly with white or green foil. 
Data for radiation sum and sunshine duration were provided by the Institute of Meteorology and Climatology, (Leibniz Universität Hannover). Measurement was made immediately adjacent to the greenhouse used for the experiments.

\section{Statistics}

The observations were counts out of two possible categories (number of whiteflies on plants treated with foil and number of whiteflies located on untreated plants), and hence, a binominal process was assumed. Consequently, the statistical analysis was based on proportions (counted whiteflies on treated plants divided by the total number of counted whiteflies), rather than on the original counts. It was assumed that, without any treatment, the individual whiteflies would be spread randomly in the flight cages giving a 50:50\% distribution. Consequently, a treatment effect was assumed if the estimated mean proportion of whiteflies located on the treated plants was significantly different from 0.5 . For each of the four different trials, separate generalised linear models running on the logit link were fitted to the observed proportions (McCullagh and Nelder 1989) such that the proportions depended on the north-south direction of the flight cage, the hours of sunshine per day and the radiation sum per day. We modelled extra-binomial variation (overdispersion) using the quasi-likelihood approach (sometimes called quasi-binomial assumption) that is described in McCullagh and Nelder (1989) or Demétrio et al. (2014). Finally, mean proportions and their confidence intervals as well as tests for the hypothesis that the estimated mean proportion differs significantly from $0.5($ alpha $=0.05)$ were calculated based on the fitted model (Lenth 2019). The statistical analysis was performed using $\mathrm{R}$ (version 3.5.3 for Windows 7). The models were fitted by the glm function and the average proportions, and their confidence intervals and the tests were calculated using the function emmeans from the emmeans package (Lenth 2019). The figures concerning spectral reflectance were made using Microsoft Excel (MS Office 2016). All other figures concerning results were made using the software RStudio (version 1.1.442) and the ggplot2 package (Wickham 2016).

\section{Results}

\section{Reflection measurement}

The spectral reflectance of the coloured foils and the different plant species are shown in Fig. 2. The lettuce plants and broccoli plants showed nearly the same peak in the green region $(\approx 550 \mathrm{~nm}, 20 \%$ reflection), but the broccoli leaf exhibited a higher spectral reflectance $(\sim 17 \%)$ in the UV-blue-region $(300 \mathrm{~nm}$ to $500 \mathrm{~nm}$ ) than all other materials (8\%), except the white foil (see below). The comparison of lettuce leaf versus yellow-green foil showed the same reflection from 300 to $470 \mathrm{~nm}(\leq 10 \%)$. Peaks of reflection of both foils were about $530 \mathrm{~nm}$, but the reflection intensity of the yellow-green foil in the green and yellow range $(500 \mathrm{~nm}$ to $600 \mathrm{~nm}$ ) was more than twice as high (46\%) as that of the lettuce (20\%), the broccoli leaves (22\%) and the medium-green foil (23\%). The white foil reflected less than $10 \%$ in the range $300-370 \mathrm{~nm}$, but towards the longer
Fig. 2 Reflectance (\%) between 300 and $700 \mathrm{~nm}$ of the different coloured foils and leaves of plant species used in experiments

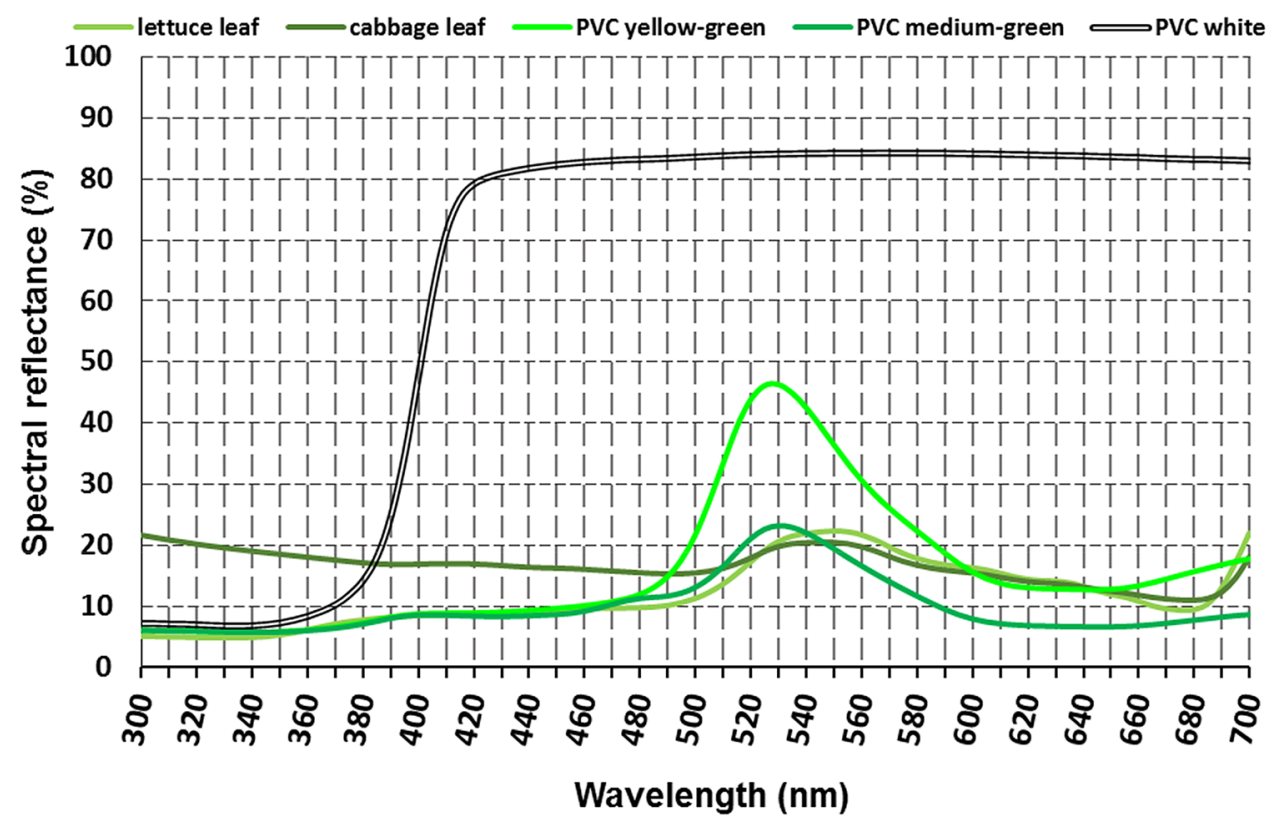


wavelength the reflection curve rose exponentially, flattening out at $440 \mathrm{~nm}$ and $80 \%$ reflection.

\section{Choice experiments}

Figure 3 a shows the proportion of recaptured $A$. proletella in the choice experiment on plants mulched with mediumgreen foil vs. bare soil. The estimated mean proportion was 0.41 which significantly $(p<0.0001)$ differs from the hypothetical 0.5 although fluctuations in repetitions over time were relatively high. On average, a reduction in infestation of $18 \%$ from the assumed 0.5 of the foil treated plants was achieved. The mean proportion of insects located on the treated plants varied between 0.5 on the 05 January 2018 and 01 February 2018 and 0.24 on the 09 January 2018.

Figure $3 \mathrm{~b}$ shows the proportion of $T$. vaporariorum on plants mulched with yellow-green foil vs. bare soil. The proportion of insects settled on treated plants varied between 0.43 on the 4 December 2017 and 0.22 on the 30 January 2018 . The mean proportion estimated from the model was 0.3 which was also significantly different $(p<0.0001)$ from the assumed 0.5 . On average, a reduction of $40 \%$ from the assumed 0.5 was achieved in infestation of foil treated plants.
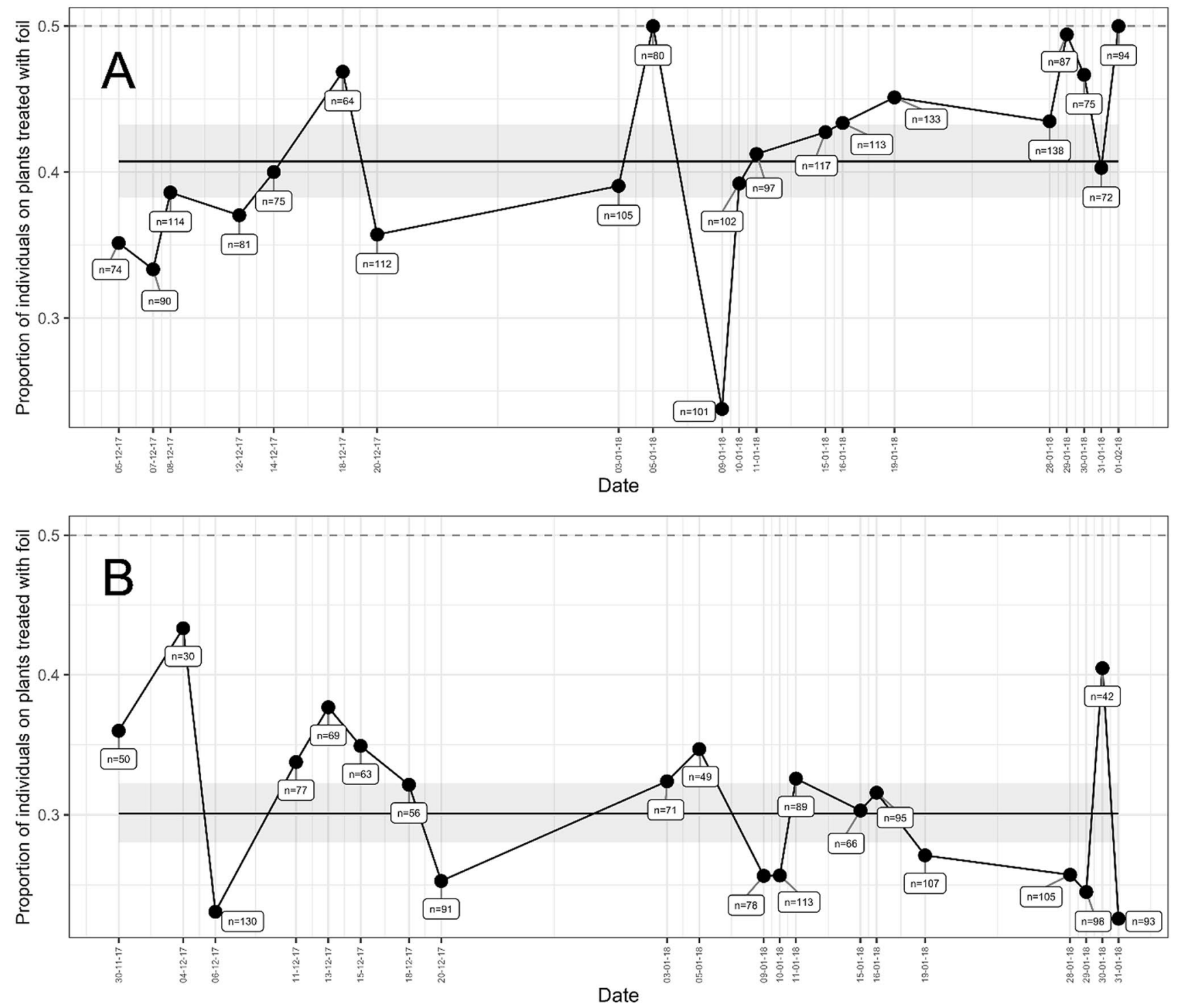

Fig. 3 Proportions of recaptured individuals of Aleyrodes proletella on plants mulched with medium-green foil versus bare soil (a) and proportions of counted individuals of Trialeurodes vaporariorum on plants mulched with yellow-green foil versus bare soil (b). The model-based average proportion across all observations is represented by the black horizontal line with its corresponding $95 \%$ confidence interval (grey area around the average proportion). The mean proportion of whiteflies on plants with foil differs significantly $(p<0.0001)$ from 0.5 (dashed line) 

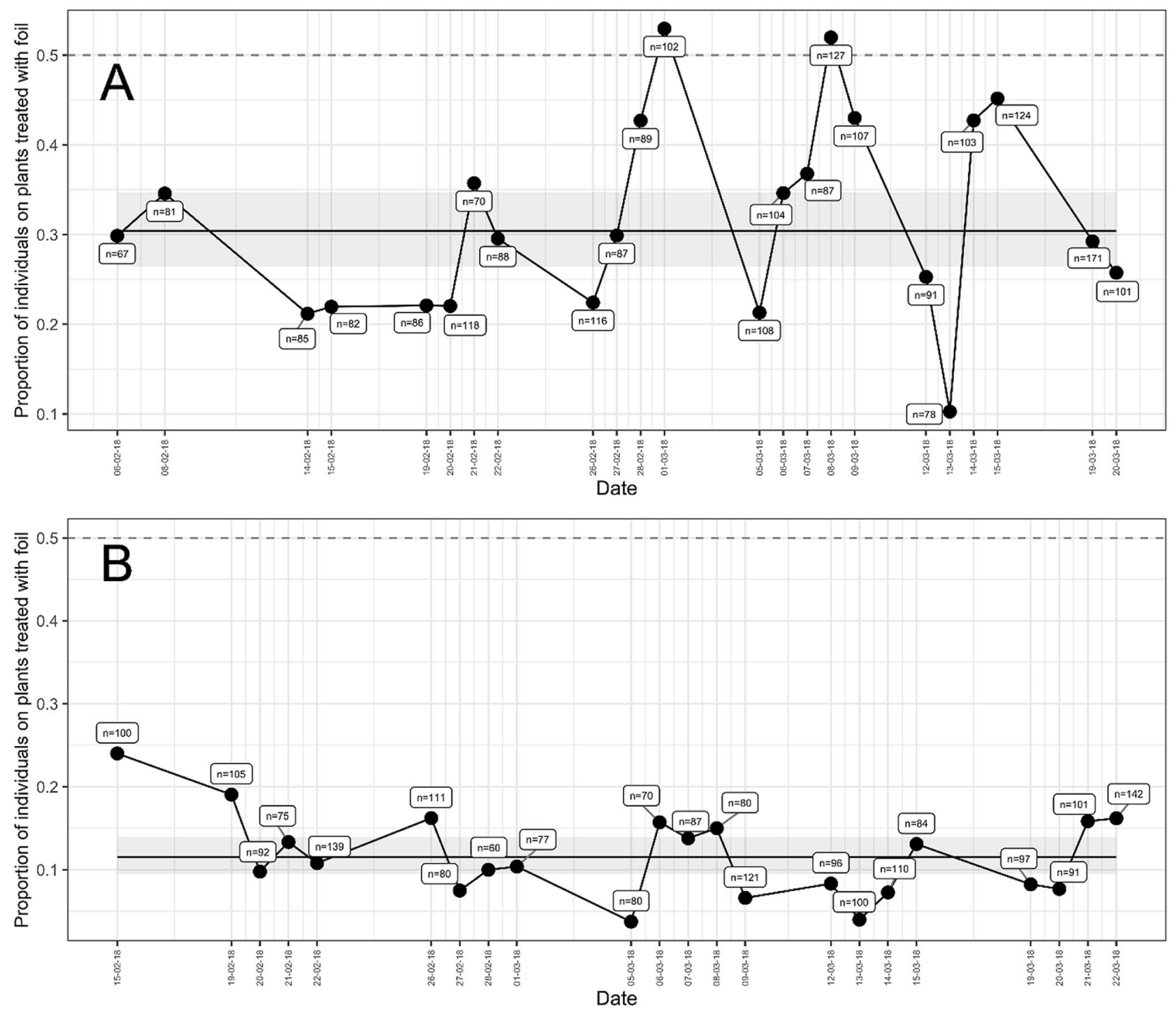

Fig. 4 Proportions of counted individuals of Aleyrodes proletella (a) and Trialeurodes vaporariorum on plants mulched with white foil versus bare soil (b). The model-based average proportion across all observations is represented by the black horizontal line with its corre-

The proportions of A. proletella recaptured on plants mulched with white foil vs. bare soil are shown in Fig. 4a. The observed proportions varied between 0.53 on the 1 March 2018 and 0.1 on 13 March 2018. The modelbased mean proportion was 0.3 , which was significantly $(p<0.0001)$ different from the assumed 0.5. An average reduction in infestation of foil treated plants of $39 \%$ was achieved, based on the assumed 0.5.

The proportion $T$. vaporariorum recaptured after $23: 45 \mathrm{~h}$ in the choice experiment on the plants mulched with white foil vs. bare soil is shown in Fig. 4b. The proportions vary between 0.24 on the 15 February 2018 and 0.03 (05 March 2018 and 13 March 2018). The estimated mean proportion sponding 95\% confidence interval (grey area around the average proportion). The mean proportion of whiteflies on plants with foil differs significantly $(p<0.0001)$ from 0.5 (dashed line)

is 0.11 . An average reduction in infestation of foil treated plants of $78 \%$ was achieved, assuming the 0.5 proportion.

\section{Discussion}

\section{Contrast variants: yellow-green foil and medium-green foil}

The preliminary test revealed that the medium-green foil did not sufficiently reduce the contrast between plants and background to disturb controlled settling by $T$. vaporariorum on lettuce. The reflection measurement also showed that the 
maximum reflection values (\%) of the medium-green foil and the lettuce plants were almost the same, but not at the same wavelength which supports this conclusion. Thus, it appears that the lettuce plants could still be visually selected by the whiteflies in contrast to the ground. The result shows that the foil colour needs to be carefully adapted to the relevant reflection properties of the crop which should be protected. These findings correspond to those of Finch and Collier (2000) and Shimoda (2018) who showed alternate behaviour to minimised contrast by several different genera and species. For aphids, it was shown in field experiments that infestation rates can be decreased by selection of the spectral reflectance by the foil material (Döring and Röhrig 2016). The yellow-green foil, on the other hand, seems to have "outshined" the lettuce plants since the percentage reflection is considerably higher than that of the lettuce. This finding fits to those of Coombe (1981) and Stukenberg (2018) who showed intensity depended behaviour of $T$. vaporariorum for same wavelength. The percentage reflectance in the yellow range of the spectra (570-600 $\mathrm{nm}$ ) by the yellow-green foil was just slightly above the reflectance (\%) by the lettuce. Even if this elicits a positive landing trigger for itself, it could be compensated by the relative high reflectance (\%) in the blue range between 470 and $490 \mathrm{~nm}$. For T. vaporariorum Stukenberg and Poehling (2019) showed clearly that the increasing amount of blue light inhibits the attracting effect by the yellow amount of the light. UV-light can also play a role in general, but for the yellow-green foil, which produces a similar spectral reflectance as lettuce between 250 and $460 \mathrm{~nm}$, this effect could not be observed.

\section{Contrast effect-settling}

This is the first study dealing with green foil to minimise contrast for whitefly control in greenhouses. Due to the lack of comparable studies with whiteflies, we discuss our findings mostly in relation to studies with aphids.

The yellow-green and the medium-green foil reduced the number of recaptured whiteflies both significantly (A. proletella, 0.41 and $T$. vaporariorum, 0.3 , regarding the assumed proportion of 0.5). This is not surprising due to the underlying mechanisms we hypothesised: The plants are not well visible to insects due to the minimised contrast between them and the ground.

The decreasing attractiveness of potential landing targets for herbivorous insects due to reduced contrast was early demonstrated with pan-trap experiments for aphids by Moericke (1955), De Barro (1991) and Döring et al. (2004). However, aphids show normally a distinct distribution flight behaviour above the crop canopy favouring the optical differentiation of target and background from above. The comparable behaviour of whiteflies is not well studied. In field experiments, however, with different whitefly species, dispersing adults were caught in higher number in traps just above the ground in contrast to those traps installed higher (Ohnesorge and Rapp 1986 (B. tabaci); Isaacs and Byrne (B. tabaci) 1998; Collins 2016 (A. proletella) and a more short distance flight behaviour within the crop canopy was deduced. If individuals in our experiment behaved the same, this could result in a reduced effect of the contrast minimising foils compared to aphids. Moreover, this effect could be influenced by the different plant structures and be stronger in the broccoli (due to its height) than the flat-growing lettuce, which would correspond to the obtained results. Nebreda et al. (2005), however, showed in choice experiments with A. proletella and different cabbage cultivars (broccoli, cauliflower and red cabbage) that plant structure plays an important role but more the cultivar in host finding and infestation.

The experimental question, however, was more focused on whether the different species were able to select its individual host with or without foil treatment. First, Jones and Chapman (1968) showed an attractive effect of green films on aphids, but spectra for the used materials were not given. Field trials with lettuce by Hommes et al. (2003) showed the high number of aphids on plants mulched with green foil, but reflectance of the used green foil at $550 \mathrm{~nm}$ was slightly lower $(\sim 20 \%)$ than those of the lettuce $(\sim 22 \%)$ which indicates that the foil was not able to minimise the contrast of plants and environment. In the experiments shown here, the differences in reflection at $550 \mathrm{~nm}$ were much higher ( $\sim 50 \%$ reflection by yellow-green foil, $22 \%$ reflection by lettuce leaves). Usually, this should result in clear settling response, if no inhibiting blue or UV light is added. Coombe (1981) showed opposite phototactic responses (positive at $550 \mathrm{~nm}$, negative at $400 \mathrm{~nm}$ ) by different monochromatic light sources. Studies by Stukenberg (2018) showed that the effect of light is not only dependent on amount of yellow and blue in the mix, but also intensity-dependent. The higher amount of whiteflies recaptured on the soil plots indicates that colour contrast may play a bigger role in landing and settling behaviour than colour itself does. This was also assumed in Hommes et al. (2003) and shown for aphids in field experiments by Döring and Röhrig (2016), where they used highly attractive background colours behind attracting trap colours with decreasing aphid catches, but mechanisms are unclear.

\section{Edge effects}

Although in our experiments we could observe a distinct reduction of infestation, the effect could have been limited by a general attracting effect of the green foil leading to more whiteflies immigrating to that plot and finally settling on plants by short distance movements. Within the plots, the green surface under the plants should possibly result in a "trap-like-effect" which may have lowered the effect of 
the green foil variants in contrast to those with white foil (see below). However, this effect cannot be validated by our experimental design, and therefore, larger plots with distinct edge properties and more detailed time sequential analysis of landing and settling of whiteflies is necessary.

\section{Reflective variants: white foil}

The use of white foil had a strong and significant influence on the number of recaptured $T$. vaporariorum on the plots. Even though it was not possible to completely prevent an infestation, the settling of $T$. vaporariorum on the plants was greatly reduced. The possible repellent effect of white foils has been shown in several studies (Jones and Chapman, 1968; Greer and Dole 2003; Hommes et al. 2003; Döring, 2004, 2014). Concerning the explanation of the mechanism behind effects of reflective foil, one major problem is a clear identification of relevant wavelength. It is not possible to differentiate, for instance, between the reflection effect in UV range $(<400 \mathrm{~nm})$ and the near-UV $(400-430 \mathrm{~nm})$ and blue range (430-490 nm), which is important if aiming for a fine-tuning of these effects. Studies dealing with "reflective foil" for repelling whitefly species are difficult to compare, as both materials and optical properties vary greatly (Greer and Dole 2003). From the studies of Moericke (1955), showing that aphid flight activity is triggered by UV (in particular the upward flight), it can be assumed that whiteflies show equal behaviour and UV reflecting ground will induce dispersion flight rather than settling (Coombe 1982; Summers and Stapelton 2002; Stukenberg 2018). Furthermore, aphids and whiteflies avoid immigration in areas reduced in ambient UV radiation (Gulidov and Poehling 2013; Mutwiwa et al. 2005; Mutwiwa and Tantau 2005; Shimoda 2018). However, in all these studies a detailed analysis of the short wavelength range is missing. Csizinszky et al. (1997) showed increasing whitefly populations in autumn on white foil in contrast to yellow, orange or aluminium foil in field experiments with Bemisia argentifolii, but reflection spectra of the used materials were not reported. Also the dorsal light reaction (Goodman 1965) could be disturbed by the reflected wavelength, which would result in leaving the area, as shown in several studies (Kring 1972; Shimoda and Honda 2013; Shimoda 2018). Since we used a white foil with low reflection in the UV range, we assume that the repellent effect is due to the high reflection intensity (brightness) in the range of 400-490 nm. This finding is analogous to those by Affeld et al. (1983), Webb et al. (1985) and recently by Stukenberg et al. (2019). Even if we can exclude the influence of UV light for the shown experiments, there are a number of possible reasons for the repellence of the other wavelength ranges. Shimoda (2018) suggests that denaturation of proteins and damaging of DNA-molecules could be involved in the toxic effect near-UV light shows in laboratory tests with insects. With different developmental stages of Drosophila melanogaster, Shibuya et al. (2018) showed increase of $\mathrm{H}_{2} \mathrm{O}_{2}$-species when the illumination wavelength was 400-470 nm. Hori et al. (2014) claimed that near-UV radiation might be more harmful to insects than UV radiation, and Stukenberg and Poehling (2019) showed repellent effects by blue $(\sim 40 \mathrm{~nm})$ light on $T$. vaporariorum. Further investigations are necessary to find out whether $T$. vaporariorum has reacted to one or more wavelengths or contrasts between them.

Under field conditions, the variants with contrast reduction have the theoretical advantage that the contrast of foil and plant is not strongly influenced by different weather scenarios, but the here relevant reflection properties of films in lower wavelength depend strongly on ambient light conditions. On the other hand, "contrast minimising" only works for species who primarily use optical contrasts for host finding, whereas the broad disorientation properties of reflective white foil could also be applicable for species who may use olfactory or other cues most of all. One important aim of this study was to achieve basic data for the development of herbivore controlling but also biodegradable mulch films, which should be applied by spraying it directly on the ground. Such films could stay in the field and finally milled under before new planting starts. Consequently, we had to choose foil colours which can be reproduced using natural pigments (food grade). For green and white foil, natural pigments and coloured soils could be used. Reflective surfaces like aluminium, silver or blue were not reproducible with food grade pigments.

\section{Experimental design}

A possible point of criticism is the use of spatially limited flight cages in a controlled environment. However, we see more advantages in this approach: on the one hand, the flight cages are changing incoming light from above, but this effect, if present, would be the same for all experimental organisms (plants and insects). On the other hand, despite the problem of cleaning routine in high greenhouses mentioned before, the cage is giving a standardised size for the experimental plots and could be reproduced by anyone else. It also inhibits crosscontamination with other glasshouse cabinets. Especially, small greenhouse cabins for experiments show a higher ratio of frame to window area and a large spatial proximity to the heating system, which we tried to avoid here (see materials and methods). The gauze distributes the incoming light more equally (like the greenhouse shading also did), preventing take-off effect on whiteflies by direct sunlight in individual subareas of the flight cage. In Addition, vegetable cultivation with additional light in shaded greenhouse is common in northern Europe to prevent heat losses, and experiments should have a practical relevance. This setup is comparable to 
the lighting regime in spring, autumn and winter cultivation of vegetables in a greenhouse. However, the preference for certain colours and the general host-finding process by insects, even if influenced by different biotic (e.g. predators) and abiotic (e.g. Weather) factors should be similar in the field. To prove this theory, field trials with the same model plants were performed the following seasons (publication in progress).

Another point is the different numbers of recaptured whiteflies, exceeding the number of 100 several times. We tried to calibrate the system of exhausting the whiteflies from the rearing by sucking 100 (visually counted) individuals into a vial, freeze them and count them again. This calibration showed normally a high accuracy of the counting; however, with a high density of individuals in the stock rearing, it was difficult to select exactly 100 individuals for each sample. For further studies, it would be also appropriate to change the point of release and introduce a platform of certain height above the plants, which would be more realistic scenario for the whitefly infestation procedure.

\section{Intraspecific aspects}

The experimental results indicate a strong correlation between host plant spectrum and wavelength-specific reactions for the tested whitefly species. In addition, host specificity, which decreases the possibility of finding hosts by chance, also increases the probability of a specific search mechanism for host finding and selection (see also Döring 2014). This may, for example, be an additional orientation aid by olfactory stimuli, which helps to overcome the optically repellent mechanism, as shown by Butler (1938) for A. proletella. This can explain the much lower and inconsistent reaction to the reflective white foil in the choice tests with this species. This effect is maybe triggered by the experimental plot size (to small) and low air movement in the greenhouse. Differences in learning capacity could also be involved in this process (Bernays and Funk 1999; Tapia et al. 2015). Controlled studies about spectral sensitivity of generalists and specialist from the same species could show if the unequal reaction is caused by visual stimuli, or if additional senses (e.g. olfactory stimuli) are involved. For aphids, it was shown that different species also show different responses to colours (Moericke 1969; Döring and Chittka 2007; Straw et al. 2011; Döring and Röhrig 2016) but experiments were not designed to evaluate intraspecific behaviour, so generalists and specialists were not tested against each other.

\section{Conclusion}

The results shown here demonstrate a high potential for the use of reflective and contrast minimising foils to reduce the infestation with phytophagous insect pests, especially if embedded in an integrated pest management (IPM) system. We have to consider that the "treatment" with the coloured foil does not show effects like chemicals do, but we do not consider this method as "standalone", it has to be included in an integrated pest management (IPM) system. But if cultivation of plants will be done with mulch foil anyway, and the additional cost of production for coloured foil would be nearly zero, also the observed relatively small effects could be a substantial improvement of the control system. Further investigations are needed to show how stable this effect is in the field and/or under more practical conditions. For this purpose, large field trials were planned. More basic and applied research on visual perception by phytophagous insects and their resulting behaviour is necessary to use generated knowledge for plant protection practice and for ecological questions.

Acknowledgements This work was funded by the Fachagentur Nachwachsende Rohstoffe (FNR), Germany, under the Grant No. 22008214/14NR082. We would like to acknowledge the constant whitefly rearing provided by Mr. Timo Michel. We would also like to acknowledge Mr. Matthias Bierschenk for providing the "experimental setup" graphic and Dr. Julia Müller for helpful advises in language and style. The authors take full responsibility for the content of this publication.

Author contributions JUN and HMP conceived and designed research. JUN conducted experiments. MM and JUN analysed data. JUN wrote the first manuscript and all authors commented on previous versions of the manuscript. All authors read and approved the manuscript.

Funding Open Access funding enabled and organized by Projekt DEAL.

\section{Compliance with ethical standards}

Conflict of interest The authors declare that they have no conflict of interest.

Open Access This article is licensed under a Creative Commons Attribution 4.0 International License, which permits use, sharing, adaptation, distribution and reproduction in any medium or format, as long as you give appropriate credit to the original author(s) and the source, provide a link to the Creative Commons licence, and indicate if changes were made. The images or other third party material in this article are included in the article's Creative Commons licence, unless indicated otherwise in a credit line to the material. If material is not included in the article's Creative Commons licence and your intended use is not permitted by statutory regulation or exceeds the permitted use, you will need to obtain permission directly from the copyright holder. To view a copy of this licence, visit http://creativecommons.org/licenses/by/4.0/.

\section{References}

Adlerz WC, Everett PH (1968) Aluminum foil and white polyethylene mulches to repel aphids and control watermelon mosaic. J Econ Entomol 61(5):1276-1279 
Affeldt HA, Thimijan RW, Smith FF, Webb RE (1983) Response of the greenhouse whitefly (Homoptera: Aleyrodidae) and the vegetable leafminer (Diptera: Agromyzidae) to photospectra. J Econ Entomol 76:1405-1409

Antignus Y, Ben-Yakir D (2004) Ultraviolet-absorbing barriers, an efficient integrated pest management tool to protect greenhouses from insects and virus diseases. In: Horowitz AR, Ishaaya I (eds) Insect pest management. Springer, Berlin

Antignus Y (2000) Manipulation of wavelength-dependent behaviour of insects: an IPM tool to impede insects and restrict epidemics of insect-borne viruses. Virus Res 71(1-2):213-220

Antignus Y, Nestel D, Cohen S, Lapidot M (2001) Ultraviolet deficient greenhouse environment affects whitefly attraction and flight behavior. Environ Entomol 30:394-399

Bernays EA, Funk DJ (1999) Specialists make faster decisions than generalists: experiments with aphids. Proc R Soc B Biol Sci 266(1415):151-156

Butler CG (1938) On the ecology of Aleurodes brassiciae Walker (Hemiptera). Trans R Entomol Soc Lond 87(13):291-311

Byrne DN, Bellows TS, Parrella MP (1990) Whiteflies in agricultural systems. In: Gerling D (ed) Whiteflies: Their Bionomics Pest Status and Management. Intercept Andover, UK, pp 227-261

Castle SJ (2006) Concentration and management of Bemisia tabaci in cantaloupe as a trap crop for cotton. Crop Prot 25(6):574-584

Chen C-H, Dubey A, Ko C-C (2007) Comparative morphological studies on two species of Aleyrodes (Hemiptera: Aleyrodidae). Pan Pac Entomol 83:244-254

Collins S (2016) The biology and ecology of aleyrodes proletella, the cabbage whitefly; a pest of brassica crops. Ph.D. thesis, University of Warwick

Coombe PE (1981) Wavelength specific behaviour of the whitefly Trialeurodes vaporariorum (Homoptera: Aleyrodidae). J Comp Physiol 144:83-90

Coombe PE (1982) Visual behaviour of the greenhouse whitefly, Trialeurodes vaporariorum. Physiol Entomol 7(3):243-251

Csizinszky AA, Schuster DJ, Kring JB (1997) Evaluation of color mulches and oil sprays for yield and for the control of silverleaf whitefly, Bemisia argentifolii (Bellows and Perring) on tomatoes. Crop Prot 16(5):475-481

Darshanee HLC, Ren H, Ahmed N, Zhang ZF, Liu YH, Liu TX (2017) Volatile-mediated attraction of greenhouse whitefly Trialeurodes vaporariorum to tomato and eggplant. Front Plant Sci 8:1285

De Barro PJ (1991) Attractiveness of four colours of traps to cereal aphids (Hemiptera: Aphididae) in South Australia. Aust J Entomol 30(4):263-264

DeBarro PJ, Carver M (1997) Cabbage whitefly, Aleyrodes proletella (L.) (Hemiptera: Aleyrodidae), newly discovered in Australia. Aust J Entomol 36(3):255-256

Demétrio CGB, Hinde J, Moral RA (2014) Models for overdispersed data in entomology. In: Ferreira CP, Godoy WAC (eds) Ecological modelling applied to entomology. Springer International Publishing, Switzerland, pp 219-259

Döring TF, Kirchner SM, Kühne S, Saucke H (2004) Response of alate aphids to green targets on coloured backgrounds. Entomol Exp Appl 113:53-62

Döring TF (2014) How aphids find their host plants, and how they don't. Ann Appl Biol 165:3-26

Döring TF, Chittka L (2007) Visual ecology of aphids-a critical review on the role of colours in host finding. Arthropod Plant Interact 1:3-16

Döring TF, Röhrig K (2016) Behavioural response of winged aphids to visual contrasts in the field. Ann Appl Biol 168:421-434

Döring TF, Kirchner SM, Skorupski P, Hardie J (2011) Spectral sensitivity of the green photoreceptor of winged pea aphids. Physiol Entomol 36:392-396
Evans GA (2007) The whiteflies (Hemiptera: Aleyrodidae) of the world: and their host plants and natural enemies. https://keys.lucid central.org/keys/v3/whitefly/PDF_PwP\%20ETC/world-whiteflycatalog-Evans.pdf. Accessed 05 Dec 2019

Feller C, Bleiholder H, Buhr L, Hack H, Hess M, Klose R, Meier U, Stauss R, Van Den Boom T, Weber E (1995) Phänologische entwicklungsstadien von gemüsepflanzen: I. zwiebel-, wurzelknollen- und blattgemüse. Nachrichtenbl Deut Pflanzenschutzd 47:193-206

Fereres A, Peñaflor MFGV, Favara CF, Azevedo KEX, Landi CH, Maluta NKP, Bento JMS, Lopes JRS (2016) Tomato infection by whitefly-transmitted circulative and non-circulative viruses induce contrasting changes in plant volatiles and vector behaviour. Viruses 8:225

Finch S, Collier RH (2000) Host-plant selection by insects-a theory based on "appropriate/inappropriate landings" by pest insects of cruciferous plants. Entomol Exp Appl 96(2):91-102

Goodman LJ (1965) The role of certain optomotor reactions in regulating stability in the rolling plane during flight in the desert 'locust, Sehis focerea gregaria. J Exp Biol 42:385-408

Gorman K, Devine G, Bennison J, Coussons P, Punchard N, Denholm I (2007) Report of resistance to the neonicotinoid insecticide imidacloprid in Trialeurodes vaporariorum (Hemiptera: Aleyrodidae). Pest Manag Sci 63:555-558

Gorman K, Hewitt F, Denholm I, Devine GJ (2001) New developments in insecticide resistance in the glasshouse whitefly (Trialeurodes vaporariorum) and the two-spotted spider mite (Tetranychus urticae) in the UK. Pest Mang Sci 58:123-130

Greer L, Dole JM (2003) Aluminum, aluminium foil, aluminiumpainted, plastic, and degradable mulches increase yields and decrease insect-vectored viral diseases of vegetables. Hort Technology 13:276-284

Gulidov S, Poehling H-M (2013) Control of aphids and whiteflies on Brussels sprouts by means of UV-absorbing plastic films. J Plant Dis Protect 120:122-130

Hardie J (1989) Spectral sensitivity for targeted flight in the black bean aphid, Aphis fabae. J Insect Physiol 35:619-626

Hommes M, Siekmann G, Piepenbrock O, Baur U, Fricke A, Thieme T (2003) Reduzierung des Blattlausbefalls an ausgewählten Gemüsekulturen durch Mulchen mit verschiedenen Materialien und Farben. Bundesanstalt für Landwirtschaft und Ernährung, Bonn, Geschäftsstelle Bundesprogramm Ökologischer Landbau. https://orgprints.org/16630/. Accessed 04 Sep 2019

Hooks CRR, Fereres A (2006) Protecting crops from non-persistently aphid-transmitted viruses: a review on the use of barrier plants as a management tool. Virus Res 120(1-2):1-16

Hori M, Shibuya K, Sato M, Saito Y (2014) Lethal effects of shortwavelength visible light on insects. Sci Rep 4:7383. https://doi. org/10.1038/srep07383

Horowitz AR, Ishaaya I (1996) Chemical control of Bemisia: management and application. In: Gerling D, Mayer RT (eds) Bemisia: taxonomy, biology, damage, control and management. Intercept Andover, Hants, pp 537-556

Isaacs R, Byrne D (1998) Aerial distribution, flight behaviour and eggload: their inter-relationship during dispersal by the sweetpotato whitefly. J Anim Ecol 67:741-750

Johnston N, Martini X (2020) the influence of visual and olfactory cues in host selection for bemisia tabaci biotype $\mathrm{b}$ in the presence or absence of tomato yellow leaf curl virus. Insects 11(2):115

Jones FR, Chapman RK (1968) Aluminum foil and other reflective surfaces to manipulate the movement of aphid vectors of plant viruses. Proc N C Branch Entomol Soc Am 23:146-148

Kennedy JS, Booth CO, Kershaw WJS (1961) Host finding by aphids in the field III visual attraction. Ann Appl Biol 49:1-21

Kring JB (1972) Flight behaviour of aphids. Annu Rev Entomol $17: 461-492$ 
Legarrea S, Weintraub PG, Plaza M, Viñuela E, Fereres A (2011) Dispersal of aphids, whiteflies and their natural enemies under photoselective nets. Biocontrol 57(4):523-532

Lenth R (2019) emmeans: Estimated marginal means, aka least-squares means $\mathrm{R}$ package version 14. https://cran.r-project.org/packa ge $=$ emmeans. Accessed 15 Oct 2020

Luo C, Jones CM, Devine G, Zhang F, Denholm I, Gorman K (2010) Insecticide resistance in Bemisia tabaci biotype Q (Hemiptera: Aleyrodidae) from China. Crop Prot 29:429-434

Martin JH (1999) The whitefly fauna of Australia (Sternorrhyncha: Aleyrodidae): a taxonomic account and identification guide. Tech Paper CSIRO Entomol 38:197

McCullagh P, Nelder JA (1989) Generalized linear models, 2nd edn. Chapman \& Hall New York, USA

Mellor HE, Anderson M (1995a) Antennal sensilla of whiteflies: Trialeurodes vaporariorum (Westwood), the glasshouse whitefly, Aleyrodes proletella (Linnaeus), the cabbage whitefly, and Bemisia tabaci (Gennadius), the tobacco whitefly (Homoptera : Aleyrodidae) part 1: external morphology. Int J Insect Morphol Embryol 24(2):133-143

Mellor HE, Anderson M (1995b) Antennal sensilla of whiteflies: Trialeurodes vaporariorum (Westwood), the glasshouse whitefly, and Aleyrodes proletella (Linnaeus), the cabbage whitefly, (Homoptera : Aleyrodidae) part 2: ultrastructure international. J Insect Morphol Embryol 24(2):145-160

Mellor HE, Bellingham J, Anderson M (1997) Spectral efficiency of the glasshouse whitefly Trialeurodes vaporariorum and Encarsia formosa its hymenopteran parasitoid. Entomol Exp Appl 83(1):11-20

Moericke V (1969) Hostplant specific colour behaviour by Hyalopterus pruni (Aphididae). Entomol Exp Appl 12:524-534

Moericke V (1955) Über die lebensgewohnheiten der geflügelten blattläuse (Aphidina) unter besonderer berücksichtigung des verhaltens beim landen. Zeitschrift für Angewandte Entomologie 37:29-91

Mound LA, Halsey SH (1978) Whitefly of the World British Museum (Natural History), Benham Press, pp 1-340. https://archive.org/ details/whiteflyofworlds00moun. Accessed 5 Dec 2019

Mound LA (1962) Studies on the olfaction and colour sensitivity of Bemisia tabaci (Genn) (Homoptera; Aleyrodidiae). Entomol Exp Appl 42:33-40

Mutwiwa UN, Borgemeister C, von Elsner B, Tantau HJ (2005) Effects of UV-absorbing plastic films on the greenhouse Whitefly Trialeurodes vaporariorum (westwood). J Econ Entomol 98(4):1221-1228

Mutwiwa UN, Tantau HJ (2005) Suitability of a uv lamp for trapping the greenhouse whitefly trialeurodes vaporariorum westwood (Hom: Aleyrodidae). CIGR E-journal, Manuscript BC 05004 vol 7 September

Nebreda M, Nombela G, Muñiz M (2005) Comparative host suitability of some brassica cultivars for the whitefly, Aleyrodes proletella (Homoptera: Aleyrodidae). Environ Entomol 34:205-209

Noldus LPJJ, van Lenteren JC (1991) Whitefly-Plant Relationships: Behavioural and Ecological Aspects. Reader P Whiteflies Their Bionomics Pest Status Manag Agric Ecosyst Environ 37(4):321-323

Nottingham SF, Hardie J, Tatchell GM (1991) Flight behaviour of the bird cherry aphid, Rhopalosiphum padi. Physiol Entomol 16(2):223-229

Ohnesorge B, Rapp G (1986) Monitoring Bemisia tabaci: a review. Agr Ecosyst Environ 17(1-2):21-27

Prokopy RJ, Owens ED (1983) Visual detection of plants by herbivorous insects. Annu Rev Entomol 28(1):337-364
Schlaeger S, Pickett JA, Birkett MA (2018) Prospects for management of whitefly using plant semiochemicals, compared with related pests. Pest Manag Sci 74(11):2405-2411. https://doi.org/10.1002/ ps.5058

Shibuya K, Onodera S, Hori M (2018) Toxic wavelength of blue light changes as insects grow. PLoS ONE 13(6):e0199266

Shimoda M (2018) Recent advances in the optical control of insect pests using light and color. In: Proceedings of the 2018 international symposium on proactive technologies for enhancement of integrated pest management of key crops, pp 87-102

Shimoda M, Honda K (2013) Insect reactions to light and its applications to pest management. Appl Entomol Zool 48:413-421

Smith HA, McSorley R (2000) Potential of field corn as a barrier crop and eggplant as a trap crop for management of Bemisia argentifolii (Homoptera: Aleyrodidae) on common bean in North Florida. Fla Entomol 83(2): 145

Springate S, Colvin J (2012) Pyrethroid insecticide resistance in British populations of the cabbage whitefly Aleyrodes proletella. Pest Manag Sci 68(2):260-267

Straw NA, Williams DT, Green G (2011) Influence of sticky trap color and height above ground on capture of alate Elatobium abietinum (Hemiptera: Aphididae) in sitka spruce plantations. Environ Entomol 40:120-125

Stukenberg N (2018) LED based trapping of whiteflies and fungus gnats: from visual ecology to application. Ph.D. thesis, Leibniz Universität Hannover

Stukenberg N, Poehling H-M (2019) Blue-green opponency and trichromatic vision in the greenhouse whitefly (Trialeurodes vaporariorum) explored using light emitting diodes. Ann Appl Biol $88: 439$

Stukenberg N, Gebauer K, Poehling H-M (2015) Light emitting diode (LED)-based trapping of the greenhouse whitefly (Trialeurodes vaporariorum). J Appl Entomol 139(4):268-279

Summers CG, Stapleton JJ (2002) Use of UV reflective mulch to delay the colonization and reduced the severity of Bemisia argentifolii (Homoptera: Aleyrodidae) infestations in cucurbits. Crop Prot 21:921-928

Tapia DH, Silva AX, Ballesteros GI, Figueroa CC, Niemeyer HM, Ramírez CC (2015) Differences in learning and memory of host plant features between specialist and generalist phytophagous insects. Anim Behav 106:1-10

Tsueda H, Tsuduki T, Tsuchida K (2014) Factors that affect the selection of tomato leaflets by two whiteflies, Trialeurodes vaporariorum and Bemisia tabaci (Homoptera: Aleyrodidae). Appl Entomol Zool 49(4):561-570

Vaishampayan SM, Kogan M, Waldbauer GP, Woolley JT (1975) Spectral specific responses in the visual behaviour of the greenhouse white-fly, Trialeurodes vaporariorum (Homoptera: Aleyrodidae). Entomol Exp Appl 18:344-356

Vaishampayan SM, Waldbauer GP, Kogan M (1975) Visual and olfactory responses in orientation of plants by greenhouse whitefly, Trialeurodes vaporariorum (Homoptera: Aleyrodidae). Entomol Exp Appl 18(4):412-422

Webb RE, Smith FF, Affeldt H, Thimijan RW, Dudley RF, Webb HF (1985) Trapping greenhouse whitefly with coloured surfaces: variables affecting efficacy. Crop Prot 4:381-393

Wickham H (2016) ggplot2: Elegant graphics for data analysis. Springer-Verlag, New York

Publisher's Note Springer Nature remains neutral with regard to jurisdictional claims in published maps and institutional affiliations. 